\title{
Four Quadrant Robust Quick Response Optimally Efficient Inverterfed Induction Motor Drive
}

Islam, S.M. Rashid, M.H.;Res. Inst., King Fahd Univ. of Pet.Miner., Dhahran;

Circuits and Systems, 1989., Proceedings of the 32nd Midwest Symposium

on;Publication Date: 14-16 Aug 1989

King Fahd University of Petroleum \& Minerals

http://www.kfupm.edu.sa

Summary

A new approach for controlling the speed of an inverter-fed induction motor which operates with variable flux for high-efficiency purposes is presented. An optimal efficiency calculator provides optimum flux and torque producing current, while a supervisory control eliminates the intricate boot-strap effect of the flux-torque loop. A model reference-based adaptive speed controller guarantees quick speed response and robustness of the drive system. Simulation results with a 100-hp motor show that up to $80 \%$ savings in controllable losses are achievable at light load, and the motor can reach rated speed in just $750 \mathrm{~ms}$. The control algorithms developed are readily implementable with present-day microprocessors

For pre-prints please write to:abstracts@kfupm.edu.sa 